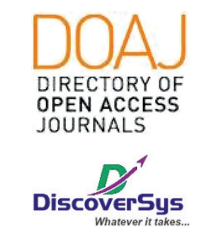

Published by DiscoverSys

\title{
Pengaruh kepatuhan pendokumentasian asuhan medis terhadap kelengkapan dokumen pengajuan klaim JKN di Instalasi Rawat Inap RSUD Badung tahun 2018
}

\author{
Raditya Putra Pratama Suryadhi, ${ }^{1 *}$ Dyah Pradnyaparamita Duarsa, ${ }^{2}$ \\ Komang Ayu Kartika Sari²
}

\section{ABSTRACT}

Background: BPJS as a health insurance institution runs the National Health Insurance (JKN) program. JKN implements a prospective financing system whereby payments made after the provision of services are in accordance with the agreement at the beginning in the form of packages. As regard with the fee, the hospital should take an effort to submit the proof document as the condition for the filing of the claim.

Aim: This study aims to determine the effect of medical documenting compliance with the completeness of the JKN claim filing documents at the inpatient installation of Badung Hospital.
Method: This study is a cross-sectional analytic study with the sample used is 120 documents of in-patient medical treatment that has been repatriated at the in-patient installation of Badung General Hospital in February 2018.

Results: This research get result that the price $r_{s}=0.861$ and p-value $=0,003$.

Conclusion: There is an effect of compliance with documenting medical care on the completeness of claim filing documents in the inpatient installation of Badung General Hospital.

Keywords: Compliance Documentation Medical Care, Document Completion Filing Claim JKN, Installation inpatient at Badung Hospital Cite This Article: Suryadhi, R.P.P., Duarsa, D.P., Sari, K.A.K. 2019. Pengaruh kepatuhan pendokumentasian asuhan medis terhadap kelengkapan dokumen pengajuan klaim JKN di Instalasi Rawat Inap RSUD Badung tahun 2018. Intisari Sains Medis 10(2): 223-226. D0I: 10.15562/ism.v10i2.298

\section{ABSTRAK}

Latar Belakang: BPJS sebagai lembaga penyelenggara jaminan kesehatan menjalankan program Jaminan Kesehatan Nasional (JKN). JKN menerapkan sistem pembiayaan prospektif dimana pembayaran yang dilakukan setelah pemberian pelayanan sesuai dengan kesepakatan diawal dalam bentuk paket. Untuk mendapatkan biaya ini, pihak rumah sakit wajib menyerahkan dokumen bukti sebagai syarat pengajuan klaim. Tujuan: Untuk mengetahui pengaruh kepatuhan pendokumentasian asuhan medis terhadap kelengkapan dokumen pengajuan klaim JKN di instalasi rawat inap RSUD Badung.
Metode: Penelitian ini merupakan penelitian cross-sectional analitik dengan sampel yang digunakan adalah rekam medik pasien rawat inap yang sudah dipulangkan di instalasi rawat inap RSUD Badung bulan Februari tahun 2018 yang memenuhi kriteria inklusi sebesar 120 dokumen.

Hasil: Penelitian ini mendapatkan hasil bahwa harga $r_{s}=0,861$ dan nilai $p=0,003$. Kesimpulan: Terdapat pengaruh kepatuhan pendokumentasian asuhan medis terhadap kelengkapan dokumen pengajuan klaim di instalasi rawat inap RSUD Badung.
'Program Studi Pendidikan Dokter Fakultas Kedokteran Universitas Udayana

2Departemen IImu Kedokteran Keluarga dan IImu Kedokteran Pencegahan Fakultas Kedokteran Universitas Udayana

${ }^{*}$ Correspondence to: Raditya Putra Pratama Suryadhi, Program Studi Pendidikan Dokter Fakultas Kedokteran Universitas Udayana

aditsaper1996@gmail.com

Diterima: 04-07-2018

Disetujui: 09-08-2018

Diterbitkan: 01-08-2019

Kata Kunci: Kepatuhan pedokumentasian asuhan medis, kelengkapan dokumen pengajuan klaim jkn, Instalasi Rawat Inap RSUD Badung Cite Pasal Ini: Suryadhi, R.P.P., Duarsa, D.P., Sari, K.A.K. 2019. Pengaruh kepatuhan pendokumentasian asuhan medis terhadap kelengkapan dokumen pengajuan klaim JKN di Instalasi Rawat Inap RSUD Badung tahun 2018. Intisari Sains Medis 10(2): 223-226. D0I: 10.15562/ism.v10i2.298

\section{PENDAHULUAN}

Pengetahuan masyarakat tentang pelayanan kesehatan di era globalisasi yang semakin melambung tinggi akan menyebabkan meningkatnya tuntutan masyarakat akan mutu pelayanan kesehatan yang lebih baik. Pelayanan di bidang kesehatan merupakan hal yang paling banyak dibutuhkan oleh masyarakat karena kesehatan adalah hal yang sangat penting bagi kehidupan manusia. Jaminan
Sosial di bidang kesehatan dilaksanakan oleh lembaga yang dibentuk pemerintah yaitu Badan Penyelenggara Jaminan Sosial (BPJS) berdasarkan UU No. 24 Tahun 2011 tentang BPJS. BPJS sebagai lembaga penyelenggara jaminan kesehatan meluncurkan program Badan Penyelenggara Jaminan Sosial (BPJS) yang mulai efektif berlaku sejak 1 Januari $2014 .^{1}$ 
JKN menerapkan sistem pembiayaan prospektif adalah dimana pembayaran yang dilakukan setelah pemberian pelayanan sesuai dengan kesepakatan diawal dalam bentuk paket. ${ }^{2}$ Untuk mendapatkan biaya ini, pihak rumah sakit wajib menyerahkan dokumen bukti sebagai syarat pengajuan klaim. Kelengkapan dokumen pengajuan klaim JKN merupakan hal yang sangat penting untuk kelancaran proses penggantian biaya pelayanan. Kelengkapan dokumen klaim JKN dapat dipengaruhi oleh kelengkapan yang berasal dari peserta (seperti fotokopi KTP, fotokopi kartu BPJS) atau dari asuhan medis (seperti resume pasien, laporan penunjang, laporan individu pasien). Penelitian di RS PKU Muhammadiyah Yogyakarta menemukan bahwa terdapat dua faktor tetinggi yang menyebabkan klaim BPJS ditolak yakni tidak lengkapnya laporan penunjang dan laporan individual pasien. ${ }^{3}$

\section{METODE}

Penelitian ini merupakan penelitian analitik korelasi terhadap pengaruh permasalahan secara obyektif, yakni antara kepatuhan pendokumentasian asuhan medis dan tingkat kelengkapan dokumen persyaratan klaim JKN. Metode yang digunakan adalah observasional menggunakan rancangan penelitian potong lintang (cross-sectional). Penelitian ini juga menggambarkan secara obyektif mengenai gambaran permasalahan dalam bentuk deskriptif. Sampel yang digunakan berupa rekam medik pasien di instalasi rawat inap di RSUD Badung.

\section{HASIL DAN DISKUSI}

Hasil analisis univariat dari penelitian di instalasi rawat inap RSUD Badung mengenai kepatuhan pendokumentasian asuhan medis didapatkan hasil bahwa pada bagian pemeriksaan fisik dan diagnosis sebanyak 3 poin merupakan kategori patuh $(23,1 \%)$ dan 10 poin merupakan kategori tidak patuh $(76,9 \%)$. Pada bagian kelengkapan resume pasien masuk dan keluar sebanyak 12 poin merupakan kategori patuh (48\%) dan 13 poin merupakan kategori tidak patuh (52\%). Pada bagian resume medis sebanyak 8 poin $(44,4 \%)$ merupakan kategori patuh dan 10 poin merupakan kategori tidak patuh $(55,6 \%)$.

Pada tabel 2 dapat disimpulkan dari hasil analisis univariat dari penelitian di instalasi rawat inap RSUD Badung mengenai kelengkapan pendokumentasian asuhan medis didapatkan hasil bahwa 2 poin $(40 \%)$ merupakan kategori lengkap terdiri

\section{Tabel 1 Kepatuhan pendokumentasian asuhan medis}

\begin{tabular}{|c|c|c|c|c|c|c|}
\hline \multirow[b]{2}{*}{ NO } & \multirow[b]{2}{*}{ ASPEK } & \multicolumn{2}{|c|}{ Patuh } & \multicolumn{2}{|c|}{ Tidak Patuh } & \multirow[b]{2}{*}{ Total } \\
\hline & & Frekuensi & $\%$ & Frekuensi & $\%$ & \\
\hline \multicolumn{7}{|c|}{ A. PEMERIKSAAN FISIK \& DIAGNOSIS } \\
\hline 1. & Kelengkapan General Consent & 13 & $10,8 \%$ & 107 & $89,2 \%$ & 120 \\
\hline 2. & $\begin{array}{l}\text { Kelengkapan Assesemen Medis Awal } 24 \\
\text { jam MRS }\end{array}$ & 59 & $49,1 \%$ & 61 & $50,9 \%$ & 120 \\
\hline 3. & $\begin{array}{l}\text { Kesesuaian Kronologis Penanganan } \\
\text { Pasien sebagai Hasil dari Assesmen Awal } \\
\text { (assesmen, pem. fisik, pempenunjang) }\end{array}$ & 103 & $85,8 \%$ & 17 & $14,2 \%$ & 120 \\
\hline 4. & Pengisianoleh DPJP & 58 & $48,3 \%$ & 62 & $51,7 \%$ & 120 \\
\hline 5. & $\begin{array}{l}\text { Verifikasioleh DPJP apabila penulisan } \\
\text { bukan oleh DPJP }\end{array}$ & 53 & $85,4 \%$ & 9 & $14,6 \%$ & 62 \\
\hline 6. & $\begin{array}{l}\text { Kelengkapan Resume Keluar atau Resume } \\
\text { Medis }\end{array}$ & 26 & $21,6 \%$ & 94 & $78,4 \%$ & 120 \\
\hline 7. & Kelengkapan pasienmasuk\&keluar & 20 & $16,6 \%$ & 100 & $83,4 \%$ & 120 \\
\hline 8. & $\begin{array}{l}\text { Kejelasan atau keterbacaan diagnose } \\
\text { medis yang ditulis pada resume pasien } \\
\text { masuk keluar }\end{array}$ & 80 & $66,6 \%$ & 40 & $33,4 \%$ & 120 \\
\hline 9. & $\begin{array}{l}\text { Kesesuaian penggunaan singkatan dalam } \\
\text { pembuatan resume medis }\end{array}$ & 108 & $90 \%$ & 12 & $10 \%$ & 120 \\
\hline 10. & $\begin{array}{l}\text { Kejelasan nama DPJP dan tandatangan } \\
\text { DPJP }\end{array}$ & 93 & $77,5 \%$ & 27 & $22,5 \%$ & 120 \\
\hline 11. & $\begin{array}{l}\text { Verifikasi oleh DPJP apabila penulisan } \\
\text { resume oleh Residen }\end{array}$ & 46 & $76,6 \%$ & 14 & $23,4 \%$ & 60 \\
\hline 12. & Kelengkapan penulisan laporan operasi & 42 & $62,6 \%$ & 25 & $37,4 \%$ & 67 \\
\hline 13. & Keterbacaan \& kejelasan tulisan dokter & 88 & $73,3 \%$ & 32 & $26,7 \%$ & 120 \\
\hline
\end{tabular}




\begin{tabular}{|c|c|c|c|c|c|c|}
\hline \multirow[b]{2}{*}{ NO } & \multirow[b]{2}{*}{ ASPEK } & \multicolumn{2}{|c|}{ Patuh } & \multicolumn{2}{|c|}{ Tdak Patuh } & \multirow[b]{2}{*}{ Total } \\
\hline & & Frekuensi & $\%$ & Frekuensi & $\%$ & \\
\hline \multicolumn{7}{|c|}{ B. KELENGKAPAN RESUME PASIEN MASUK \& KELUAR } \\
\hline 14. & Identitas Pasien & 62 & $51,6 \%$ & 58 & $48,4 \%$ & 120 \\
\hline 15. & Nomor Rekam Medik & 115 & $95,8 \%$ & 5 & $4,2 \%$ & 120 \\
\hline 16. & Status Perkawinan & 112 & $93,3 \%$ & 8 & $6,7 \%$ & 120 \\
\hline 17. & Alamat Pasien & 113 & $94,1 \%$ & 7 & $5,9 \%$ & 120 \\
\hline 18. & Nama Penanggungjawab & 75 & $62,5 \%$ & 45 & $37,5 \%$ & 120 \\
\hline 19. & Alamat Keluarga Terdekat & 68 & $56,6 \%$ & 52 & $43,4 \%$ & 120 \\
\hline 20. & Riwayat Alergi & 82 & $68,3 \%$ & 38 & $31,7 \%$ & 120 \\
\hline 21. & Cara Masuk Pasien & 110 & $91,6 \%$ & 10 & $8,4 \%$ & 120 \\
\hline 22. & Cara Penerimaan Melalui & 115 & $95,8 \%$ & 5 & $4,2 \%$ & 120 \\
\hline 23. & Jenis Pasien & 107 & $89,1 \%$ & 13 & $10,9 \%$ & 120 \\
\hline 24. & Tanggal Masuk & 117 & $97,5 \%$ & 3 & $2,5 \%$ & 120 \\
\hline 25. & Bagian, Ruang, Kelas & 112 & $93,3 \%$ & 8 & $6,7 \%$ & 120 \\
\hline 26. & Diagnosa Masuk & 107 & $89,1 \%$ & 13 & $10,9 \%$ & 120 \\
\hline 27. & $\begin{array}{l}\text { Penyebab luar cidera \& keracunan/ } \\
\text { morfologi neoplasma }\end{array}$ & 27 & $22,5 \%$ & 93 & $77,5 \%$ & 120 \\
\hline 28. & $\begin{array}{l}\text { Nama operasi, Jenis Operasi, Jenis } \\
\text { Anestesi, Tanggal, NomorKode }\end{array}$ & 71 & $59,1 \%$ & 49 & $40,9 \%$ & 120 \\
\hline 29. & Imunisasi yang diperoleh & 21 & $17,5 \%$ & 99 & $82,5 \%$ & 120 \\
\hline 30. & $\begin{array}{l}\text { Pengobatan Radiotherapi/ Kedokteran } \\
\text { Nuklir }\end{array}$ & 23 & $19,1 \%$ & 97 & $80,9 \%$ & 120 \\
\hline 31. & Transfusi Darah & 70 & $58,3 \%$ & 50 & $41,7 \%$ & 120 \\
\hline 32. & Riwayat terjatuh dalam perawatan & 68 & $56,6 \%$ & 52 & $43,4 \%$ & 120 \\
\hline 33. & Tanggal keluar\& lama dirawat & 61 & $50,8 \%$ & 59 & $49,2 \%$ & 120 \\
\hline 34. & Diagnosa Akhir Utama \& Sekunder & 104 & $86,6 \%$ & 16 & $13,4 \%$ & 120 \\
\hline 35. & Keadaan keluar RSUD Badung & 98 & $81,6 \%$ & 22 & $18,4 \%$ & 120 \\
\hline 36. & Cara Keluar & 93 & $77,5 \%$ & 27 & $22,5 \%$ & 120 \\
\hline 37. & Nama Jelas \& Tanda Tangan DPJP & 99 & $82,5 \%$ & 21 & $17,5 \%$ & 120 \\
\hline \multicolumn{7}{|c|}{ C. RESUME MEDIS } \\
\hline 38 & Identitas Pasien & 67 & $55,8 \%$ & 53 & $44,2 \%$ & 120 \\
\hline 39 & Tanggal MRS \&Tanggal Keluar & 87 & $72,5 \%$ & 33 & $27,5 \%$ & 120 \\
\hline 40 & Riwayat Alergi & 69 & $57,5 \%$ & 51 & $42,5 \%$ & 120 \\
\hline 41 & Pemeriksaan Fisik & 99 & $82,5 \%$ & 21 & $17,5 \%$ & 120 \\
\hline 42 & $\begin{array}{l}\text { Investigasi; Laboratprium, X-Ray, USG, } \\
\text { dll }\end{array}$ & 93 & $77,5 \%$ & 27 & $22,5 \%$ & 120 \\
\hline 43 & Diagnosis & 108 & $90 \%$ & 12 & $10 \%$ & 120 \\
\hline 44 & Konsultasi & 75 & $62,5 \%$ & 45 & $37,5 \%$ & 120 \\
\hline 45 & Terapi saat dirawat & 105 & $87.5 \%$ & 35 & $13,5 \%$ & 120 \\
\hline 46 & Perkembangan Penyakit & 105 & $87,5 \%$ & 35 & $13,5 \%$ & 120 \\
\hline 47 & Kondisi Saat Keluar & 99 & $82,5 \%$ & 21 & $17,5 \%$ & 120 \\
\hline 48 & Prognosis & 102 & $85 \%$ & 18 & $15 \%$ & 120 \\
\hline 49 & Penyebab Langsung Kematian & 56 & $46,6 \%$ & 64 & $53,4 \%$ & 120 \\
\hline 50 & Masalah yang masih ada & 55 & $45,8 \%$ & 65 & $54,2 \%$ & 120 \\
\hline 51 & Rekomendasi & 83 & $69,1 \%$ & 37 & $30,9 \%$ & 120 \\
\hline
\end{tabular}


Tabel 1 Continue

\begin{tabular}{|c|c|c|c|c|c|c|}
\hline \multirow[b]{2}{*}{ NO } & \multirow[b]{2}{*}{ ASPEK } & \multicolumn{2}{|c|}{ Patuh } & \multicolumn{2}{|c|}{ Tdak Patuh } & \multirow[b]{2}{*}{ Total } \\
\hline & & Frekuensi & $\%$ & Frekuensi & $\%$ & \\
\hline 52 & Diet & 56 & $46,6 \%$ & 64 & $53,4 \%$ & 120 \\
\hline 53 & Tanda Tangan\& Nama Jelas & 98 & $81,6 \%$ & 22 & $18,4 \%$ & 120 \\
\hline 54 & DPJP & 111 & $92,5 \%$ & 9 & $7,5 \%$ & 120 \\
\hline 55 & KeluhanUtamaSaat MRS & 93 & $77,5 \%$ & 27 & $22,5 \%$ & 120 \\
\hline
\end{tabular}

Tabel 2 Kelengkapan dokumen pengajuan klaim JKN di Instalasi Rawat Inap RSUD Badung

\begin{tabular}{lcccccc}
\hline & \multicolumn{2}{c}{ Lengkap } & & \multicolumn{2}{c}{ Tidak Lengkap } & \\
\cline { 2 - 3 } Poin & frekuensi & $\%$ & & Frekuensi & $\%$ & Total \\
\hline $\begin{array}{l}\text { Assessment, pemeriksaan fisik, } \\
\text { dan pemeriksaan penunjang }\end{array}$ & 103 & 85,8 & & 17 & 14,2 & 120 \\
Diagnosis medis & 107 & 89,1 & & 13 & 10,9 & 120 \\
Tindakan medis & 42 & 62,6 & & 25 & 37,6 & 67 \\
Resume medis & 87 & 72,5 & & 33 & 27,5 & 120 \\
Resume masuk dan keluar & 71 & 59,1 & & 49 & 40,8 & 120 \\
\hline
\end{tabular}

dari assessment, pemeriksaan fisik, dan pemeriksaan penunjang serta diagnosis medis sedangkan terdapat 3 poin $(60 \%)$ yang merupakan kategori tidak lengkap yang terdiri dari tindakan medis, resume medis, dan resume masuk dan keluar.

Penelitian ini memiliki hasil yang serupa dengan penelitian yang dilakukan oleh Malonda tahun 2015 yang memperoleh hasil yaitu pengajuan klaim BPJS Kesehatan pada rekapitulasi pelayanan belum dilakukan secara menyeluruh dan terpadu. Pengisian dan pencatatan pada status rekam medis untuk kelengkapan klaim diserahkan kepada petugas rekam medis, tidak terjalinin koordinasi, dan kerja tim antara perawat pelaksana dan petugas rekam medis. Hambatan dari rekapitulasi data pasien tersebut berdampak pada terjadinya keterlambatan klaim BPJS kesehatan di RSUD Dr Sam Ratulangi Tondano. ${ }^{4}$ Pada tabel 1 dan 2, Spearman's rho diperoleh harga $\mathrm{r}_{\mathrm{s}}=0,861$ dan nilai $\mathrm{p}=0,003$ (nilai $\mathrm{p}<0,01$ yang artinya Ho ditolak). Rincian tersebut menunjukkan bahwa terdapat pengaruh kepatuhan pendokumentasian asuhan medis terhadap kelengkapan dokumen pengajuan klaim di instalasi rawat inap RSUD Badung.

Hasil dari penelitian ini sejalan dengan penelitian yang dilakukan oleh Noviasari pada tahun 2016 yang menyatakan bahwa terdapat hubungan yang signifikan antara kelengkapan informasi denganpersetujuan klaim BPJS di RSUD Kabupaten Sukoharjo dengan nilai $\mathrm{p}=0,001 .{ }^{5}$ Hasil penelitian ini juga sejalan dengan penelitian Ulfah pada tahun 2013 mengenai hubungan kelengkapan dokumen rekam medis dengan persetujuan klaim jamkesmas di RSI Sultan Agung Semarang dengan nilai $\mathrm{p}=$ $0,003 .{ }^{6}$

\section{SIMPULAN}

Berdasarkan hasil penelitian ini diperoleh simpulan bahwa terdapat pengaruh kepatuhan pendokumentasian asuhan medis terhadap kelengkapan dokumen pengajuan klaim JKN di instalasi rawat inap RSUD Badung.

\section{DAFTAR PUSTAKA}

1. Badan Penyelenggara Jaminan Sosisal Kesehatan; 2015. Fasilitas BPJS Diambil dari http://bpjs-kesehatan.go.id/ bpjs/index.php/pages/detail/2015/14. diakses pada tanggal 30 juni 2015

2. Irmawati, Sugiharto, Susanto, E., dan Astrianingrum, M. Peningkatan Mutu Perekam Medis dan Informasi Kesehatan Melalui Sertifikasi Koder di Era MEA. Semarang; APTIRMIKI ISBN: 978-602-6363-05-3; 2016: 124-130

3. Megawati, L. dan Pratiwi, R.D. Faktor-Faktor Penyebab Pengembalian Berkas Persyaratan Klaim BPJS Pasien Rawat Inap di RS PKU Muhammadiyah Yogyakarta. Jurnal Kesehatan Vokasional. 2016; 1: 1

4. Malonda, T.D., Rattu, A.J.M., dan Soleman, T. Analisis Pengajuan Klaim Badan Penyelenggara Jaminan Sosial (BPJS) Kesehatan di RSUD Dr. Sam Ratulangi Tondano. JIKMU. 2015; 5(2b): 436-447.

5. Noviasari, Tri. 2016. Hubungan Kelengkapan Informasi dengan Persetujuan Klaim BPJS di RSUD Kabupaten Sukoharjo tahun 2016. Surakarta: Universitas Muhammadiyah Surakarta

6. Ulfah, S. Hubungan Kelengkapan Dokum Rekam Medis dengan Persetujuan Klaim Jamkesmas oleh Verifikator dengan Sistem Ina CBG'S Periode Triwulan IV tahun 2011 di RSI Sultan Agung Semarang. Jurnal: Kesehatan Masyarakat. Semarang: Jurusan Kesehatan Masyarakat, Fakultas Kesehatan, Universitas Dian Nuswantoro. Semarang; 2013.

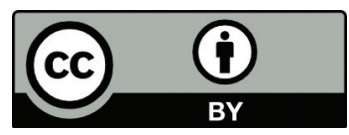

This work is licensed under a Creative Commons Attribution 